\title{
Neoadjuvant trials in ER+ breast cancer: A tool for acceleration of drug development and discovery
}

\author{
Angel L. Guerrero-Zotano and Carlos L. Arteaga \\ Departments of Medicine and Cancer Biology; Breast Cancer Program, Vanderbilt-Ingram Cancer \\ Center; Vanderbilt University Medical Center, Nashville, Tennessee 37232
}

\begin{abstract}
Neoadjuvant therapy trials offer an excellent strategy for drug development and discovery in breast cancer, particularly in triple negative and HER2-overexpressing subtypes, where pathologic complete response is a good surrogate of long term patient benefit. For estrogen receptor (ER)positive breast cancers, however, use of this strategy has been challenging because of the lack of validated surrogates of long term efficacy and the overall good prognosis of the majority of patients with this cancer subtype. We review below the clinical benefits of neodjuvant endocrine therapy for ER+/HER2-negative breast cancer, its use and limitations for drug development, prioritization of adjuvant and metastatic trials, and biomarker discovery.
\end{abstract}

\section{INTRODUCTION}

New drugs for breast cancer traditionally have been first developed and approved in patients with metastatic disease, followed then by trials to support their use in the adjuvant (postoperative) setting. The adjuvant indication is generally achieved after completion of large randomized clinical trials with long follow up to detect differences in the rate of relapse. Under this scenario, a new drug or combination may take more than a decade for it to be approved for the treatment of patients with early breast cancer since first tested in patients with metastatic disease. A fundamental change in this paradigm happened in 2013 when the FDA approved the rate of pathologic complete response (pCR) after neoadjuvant chemotherapy, that is absence of cancer in the breast and lymph nodes in the surgical specimen, as a surrogate marker of long term outcome in order to support accelerated approval (1). The advantages of this approach, to be discussed herein, are many. For example, the rate of $\mathrm{pCR}$ can be evaluated just in months and, if the difference is significant, the required sample size for the trial may not be large. However, the final full approval of such drugs is still dependent on demonstration of an improvement in event-free survival.

Recently, an increasing number of neoadjuvant trials are testing new drugs in combination with endocrine therapy in patients with estrogen receptor-positive (ER+) breast cancer. However, these trials are more challenging than trials of neoadjuvant chemotherapy and/or anti-HER2 therapy in patients with triple negative or HER2+ breast cancer, respectively. A

Correspondence: Carlos L. Arteaga, MD, Division of Oncology, VUMC, 2220 Pierce Avenue, 777 PRB, Nashville, TN 37323-6307, Tel. 6159360975 or -1919, Fax 615343 7602, carlos.arteaga@vanderbilt.edu. 
main limitation is that $\mathrm{pCR}$ is uncommon after neoadjuvant endocrine therapy (NET) and, thus, not an effective surrogate of long term outcome in patients with ER+ early breast cancer. Second, failure to achieve a pCR does not imply poor patient outcome since these patients still receive 5-10 years of adjuvant endocrine therapy. Third, many ER+ breast cancers are likely cured with local treatment and standard adjuvant endocrine treatment, which is also informed by several well validated prognostic gene signatures. All these reasons, plus the lack of a clinical endpoint that would predict event-free survival, argue against testing new drugs, sometimes with limited safety data available, before surgery of hormone-dependent tumors with a good prognosis. Hence, there is a need to optimize NET trial designs, and identify suitable target patient populations and meaningful clinical endpoints for this approach.

Therapy-induced changes in the proliferation marker Ki67 and the preoperative endocrine prognostic index (PEPI), a composite score of post-treatment ER, Ki67, tumor size and axillary nodal status, are widely used markers of response to antiestrogens in NET trials. Although examples are still limited, a high post-treatment Ki67 score and a high PEPI score have been shown to correlate with an increased risk of relapse. Besides providing an individual in vivo test of antiestrogen therapy, the neoadjuvant platform offers a unique opportunity to interrogate biomarkers of response and mechanisms of resistance in the posttreatment residual cancer. For example, 'acquired' or enriched somatic alterations, gene expression profiles and/or proteomic changes in the surgically resected treated tumors could identify biomarkers and/or effectors of drug resistance. In this critical review, we have analyzed the neoadjuvant endocrine therapy platform as a model for drug development and discovery, and its strengths and pitfalls, with a focus on how to best integrate predictive biomarkers into novel clinical trial designs.

\section{CLINICAL BENEFITS OF NEOADJUVANT ENDOCRINE THERAPY}

\section{Avoidance of surgery in frail/older patients}

Neoadjuvant endocrine therapy with tamoxifen was first used as an alternative to standard surgery in older women with early breast cancer $(2,3)$. This approach avoided the inconvenience of surgery, chemotherapy and/or radiotherapy, resulting in a $60 \%$ responses rate and also identified ER as a predictive biomarker of benefit: Nearly $100 \%$ of ER-negative tumors were unresponsive compared to a clinical benefit rate of $80 \%$ among ER+ tumors, many with long lasting responses $(4,5)$. These encouraging results triggered several randomized controlled trials comparing tamoxifen vs. mastectomy in elderly patients. A metanalysis of these studies reported an increase risk of local failure but similar breast cancer-specific and overall survival for neoadjuvant tamoxifen vs surgery followed by adjuvant tamoxifen (6). The efficacy of aromatase inhibitors (AIs) in this context has not been addressed in randomized trials, but indirect comparisons from cohort studies suggest they are superior over tamoxifen, with higher clinical benefit and lower diseases progression rates. The high median time to progression ( $\sim 9$ months), duration of clinical benefit ( $\sim 30$ months), and low toxicity make definitive primary endocrine therapy an attractive treatment choice for patients with low risk ER+ breast cancer and shorter life expectancy (7). 


\section{Increasing likelihood of breast conserving surgery}

Neoadjuvant endocrine therapy is also used with the aim of reducing tumor size to allow breast conserving surgery and/or improve breast cosmesis. Third generation AIs (letrozole, anastrozole, exemestane) have been compared to tamoxifen in several randomized trials showing superior response rates ( $76 \%-37 \%$ vs $40 \%-36 \%$ ), and eligibility for breast conservation ( $45 \%-36 \%$ vs $35 \%-20 \%)(8)$.

\section{Alternative to neoadjuvant chemotherapy}

In postmenopausal women (up to 70 years of age) with ER+ breast cancer, adjuvant chemotherapy yields similar risk reduction in mortality than in postmenopausal women with ER-negative cancer, but a marginal absolute gain in overall survival compared to adjuvant endocrine therapy (9). In addition, chemotherapy is associated with toxicities (myelodysplastic syndrome, cardiac dysfunction, permanent neuropathy) of difficult justification in patients with good overall prognosis. Further, prognostic tests, such as Mammaprint or Oncotype Dx, have helped identify those patients with a good prognosis where adjuvant chemotherapy can be safely omitted $(10,11)$. Two randomized phase II trials of neoadjuvant endocrine therapy vs. chemotherapy showed a similar response and rate of breast conservation for both treatment arms with substantially less toxicity with endocrine treatment $(12,13)$. The predictive value of the 21 gene signature Oncotype Dx for response to neoadjuvant endocrine therapy has been evaluated in a prospective study where patients were treated with preoperative exemestane for 6 months (14). Patients with a low recurrence score (RS) exhibited a clinical response rate of 59\% and a breast conservation rate of $91 \%$ compared to $20 \%$ and $47 \%$, respectively, in patients with a high RS. Thus, for many patients with low risk ER+ early breast cancer who want to avoid total mastectomy, NET is a medically reasonable option.

\section{Optimal duration of neoadjuvant endocrine therapy}

Three to four months has been the standard duration of most trials of NET. However, there is general consensus that this length of treatment is insufficient to reach maximal tumor response. To our knowledge, no studies have formally investigated the optimal duration of NET. More recent nonrandomized studies suggest that some tumors benefit from a longer duration (6-12 months) of anti-ER treatment (15-17).

Despite all these efficacy data (summarized in Table 1), NET is still underused and currently only $3 \%$ of eligible patients in the US receive this presurgical systemic treatment (18).

\section{NEOADJUVANT ENDOCRINE THERAPY AS A PLATFORM FOR DRUG DEVELOPMENT}

Neoadjuvant endocrine therapy not only confers clinical benefit to patients with ER+ breast cancer but also provides important prognostic information and is an excellent platform for clinical trial prioritization and discovery of mechanisms of drug resistance. 


\section{Efficacy and prediction of long-term outcome}

It is well established that patients with breast cancer who achieve a pCR after neoadjuvant chemotherapy and anti-HER2 therapy exhibit a good long term outcome. On the other hand, those patients with residual triple negative cancer in the breast following neoadjuvant chemotherapy are at risk of metastatic recurrence and death (19). This paradigm does not apply to luminal ER+ tumors (20), as 3-4 months of NET virtually do not produce pCR (8), thus limiting its use as a biomarker predictive of long term benefit in patients with this breast cancer subtype.

Neoadjuvant endocrine therapy has been shown to induce downregulation of gene expression signatures of cell cycle progression, and ER regulated proteins such as $\mathrm{PgR}$ and TTF1, and a reduction in ER phosphorylation at Serine 118, a marker of ER transcriptional activity (21-23). However, none of these direct pharmacodynamic biomarkers of antiestrogen action has been sufficiently studied as a measurement of therapeutic efficacy. Since antiestrogen therapy mainly induces cell cycle arrest, markers of tumor cell proliferation have been used to measure the in situ action of these drugs. The antigen Ki67 detected by immunohistochemistry is currently the most used marker to estimate tumor cell proliferation. Ki67 is expressed in proliferating tissues, in all cell cycle phases, is absent in quiescent cells, and correlates well with others markers of proliferation such as the S-phase fraction, mitotic index and/or in vivo uptake of bromodeoxyuridine (24).

A low Ki67 score in response to NET predicts for a good long term outcome, while high levels have been associated with an increased risk of breast cancer recurrence. Main evidence for this comes from three neoadjuvant studies: the IMPACT trial (25) comparing anastrozole, tamoxifen or the combination for 12 weeks, the P024 trial (22) comparing letrozole and tamoxifen for 4 months, and the ACOSGZ1031 (26) trial which compared head to head the performance of letrozole, anastrozole and exemestane for 4 months. The Ki67 score, measured as a continuous variable after natural log transformation, at 2 weeks in IMPACT, at 16 weeks in P024, and at 2-4 weeks in ACOSOGZ1031 was predictive of relapse free survival (RFS) in multivariate analysis, while the pretreatment Ki67 was not $(27,28)$. In the IMPACT trial, when the change in Ki67 was introduced in the multivariable model (instead of the absolute Ki67 score at 2 weeks), the former was not predictive of RFS. Thus, the absolute levels of on-treatment Ki67 is a useful biomarker with prognostic and predictive ability since integrates both the intrinsic proliferative rate and the response to endocrine therapy. A Ki67>10\% after 2 or 4 weeks of endocrine therapy has been suggested as cut-off for early identification of non-responders with increased risk of relapse. About $20 \%$ of patients fall into this category after initiation of neoadjuvant AIs (26).

In the P024 study, in addition to Ki67, other tumor features such as tumor size, number of axillary lymph nodes and ER status measured in the surgical specimen after NET, were associated with long term outcome in a multivariate analysis. This analysis served to develop the PEPI score, a prognostic biomarker that distinguishes between sensitive and resistant disease as a function of the risk of relapse $(28,26)$. Thus, patients with PEPI score 0 [ypT1-2, ypN0, post-Ki67 $2.7 \%$ (natural $\log \leq 1$ ), ER+], have a very low risk of relapse ( $<4 \%$ at 5 years) with endocrine therapy alone. There is also a correlation between on treatment levels of Ki67 and PEPI score: Patients with Ki67 >10\% after 2-4 weeks of 
estrogen deprivation with an AI have a probability between $0 \%$ to $5 \%$ of achieving a PEPI score 0 at surgery (29). Finally, the probability of achieving a PEPI score 0 is greater for patients with Luminal A (27\%) than Luminal B tumors (10\%) (30).

The Residual Cancer Burden (RCB) index is another biomarker of response to neodjuvant chemotherapy that is increasingly used in NET studies. The RCB index evaluates 5 posttreatment variables: 2-dimension tumor bed, cellularity, percentage of carcinoma in situ, number of metastatic lymph nodes, and the diameter of the largest nodal metastases. It classifies the surgical specimen into four categories: RCB-0 (pCR), RCB-I (minimal residual disease), RCB-II (moderate residual disease) and RCB-III (extensive residual disease). RCB is able to predict risk of relapse after neoadjuvant chemotherapy, which is highest for RCBIII (53.6\%) and similar for RCB-0 and RCB-I (2.4\% and 5.4\%, respectively) $(31,32)$. Interestingly, the incorporation of Ki67 into RCB, improved the prognostic ability of each Ki67 and RCB alone (33). Some NET studies have incorporated RCB as an end-point but, to our knowledge, there are no definitive reports of the prognostic performance of RCB in this setting. Nonetheless, the incorporation of Ki67 and also ER status into RCB warrants further investigation.

\section{Patient outcome after neoadjuvant endocrine therapy predicts results from adjuvant and metastatic studies}

In the IMPACT and P024 trials, short term treatment with an AI reduced the Ki67 score more potently than tamoxifen. This difference correlated with the outcome of large adjuvant trials where both drugs were compared. In IMPACT, following 2 and 12 weeks of treatment, anastrozole suppressed Ki67 by $76 \%$ and $82 \%$, respectively, compared to tamoxifen by $59 \%$ and $62 \%$, and the combination of both drugs by $64 \%$ and $61 \%$. These differences paralleled the outcome of the same three treatment arms in the large adjuvant ATAC trial which enrolled more than 9,000 women (34). After a median follow up of 30 months, anastrozole significantly improved DFS over tamoxifen and the combination whereas DFS was similar in the tamoxifen and combination arms. It can be argued that had the results of IMPACT been known before the ATAC trial, these data would have provided a rationale for elimination of the combination arm in ATAC, thus significantly reducing the size, duration and cost of the adjuvant study. In the P024 study, 16 weeks of treatment letrozole was superior to tamoxifen in suppressing Ki67 (87\% vs 75\%, respectively). This result also mirrors the results of the large BIG 1-98 adjuvant trial, which showed superiority of letrozole over tamoxifen in terms of DFS (35). Conversely, in the ACOSOGZ1031 trial (30), the equivalent rate of Ki67 suppression after short term therapy with all three AIs, agrees with the equivalent efficacy observed in adjuvant trials between anastrozole and exemestane (36) and between letrozole and anastrozole (37).

Results from NET trials in early stage treatment naïve breast cancer have correlated with those from similar studies in patients with metastatic breast cancer, suggesting they can be used as a filter to prioritize trials in metastatic disease. For example, the NEO-MONARCH study compared anastrozole vs. the CDK4/6 inhibitor abemaciclib vs. both drugs. After 2 weeks, the combination induced a more potent cell cycle arrest (defined as Ki67 $<2.7 \%$ or natural logarithm <1) than anastrozole alone $(66 \%$ vs $15 \%)(38)$. In another study, Ma et al. 
showed that addition of the CDK4/6 inhibitor palbociclib to anastrozole also resulted in more frequent cell cycle arrest compared to the aromatase inhibitor alone (39). These data parallel results from randomized trials showing the superiority of combinations of each palbociclib and ribociclib with letrozole over letrozole and placebo in patients with advanced ER+ breast cancer (40-43). Another example is the NEWEST study (44), which helped establish the optimal dose of the ER antagonist fulvestrant $(500 \mathrm{mg})$ on the basis of greater suppression of Ki67 compared to the lower dose of $250 \mathrm{mg}$. This difference mirrored the results of the phase III CONFIRM trial in advanced breast cancer which also showed superiority of the 500-mg dose (45). Table 2 summarizes results of NET studies and their parallel adjuvant trials or trials in patients with metastatic disease.

\section{Pharmacodynamic assessment of drug action}

The neoadjuvant setting is also a good platform for pharmacodynamic studies to confirm drug target engagement. An illustrative example is the PreOperative Palbociclib trial (POP) where patients with newly diagnosed operable ER+ breast cancer were treated for 2 weeks with the CDK4/6 inhibitor palbociclib followed by surgery. This study showed significant inhibition of phosphorylation of the Retinoblastoma protein $(\mathrm{Rb})$, the molecular target of the CDK4/cyclin D1 complex, in the treated surgical specimen compared to the pre-treatment biopsy. Inhibition of $\mathrm{P}-\mathrm{Rb}$ correlated with drug-induced inhibition of tumor cell proliferation (46). Other examples are presurgical studies with the hypo-insulinemic drug metformin which showed drug-induced inhibition of tumor cell proliferation (Ki67), insulin receptor expression, and phosphorylation of ERK, AKT, AMPK and acetyl coenzyme A $(47,48)$, thus unmasking a role for insulin and TORC1 signaling in breast cancer progression. These studies support a current large adjuvant study of metformin in breast cancer (NCT01101438). The molecular effects of metformin do not overlap with those of AIs, thus suggesting the possibility of additive effects when combined. This possibility is being tested in the randomized METEOR trial (NCT015893670) where 200 patients will be randomized to 6 months of neoadjuvant treatment with letrozole and metformin or placebo.

\section{Go vs. no go signal for large adjuvant and metastatic trials}

With the large expansion of targeted therapies and rational potential combinations with standard treatments, it will be close to impossible to test all these combinations in the adjuvant setting and determine their true anti-(micro) metastatic potency using survival as an endpoint. The pre-operative therapy setting should provide a clinical research platform where novel combinations can be compared and triaged using endpoints that correlate with long term outcome. An illustrative example is provided by trials with EGFR tyrosine kinase inhibitors (TKIs). In these preoperative studies, the combination anastrozole and gefitinib was not superior to anastrozole alone (49). This result was consistent with the results of randomized trials of anastrozole or tamoxifen \pm EGFR TKIs in metastatic disease (50-52), thus providing one example of a negative neoadjuvant trial that could have spared three randomized negative trials in patients with advanced disease. Conversely, the high activity of palbociclib in the neoadjuvant setting $(39,40)$, supports two large ongoing phase III adjuvant trials: the PENELOPE-B study of standard endocrine therapy \pm palbociclib for one year in patients with ER+ breast cancer and residual disease after neoadjuvant chemotherapy (NCT01864746); and the PALLAS study of standard endocrine therapy \pm palbociclib for 
two years in patients with stage II-III ER-positive breast cancer (NCT02513394). We speculate that had the results of the neoadjuvant trials with palbociclib and abemaciclib (NEO-MONARCH; discussed above) been negative, they would have been a deterrent to adjuvant trials with CDK4/6 inhibitors.

Recently, the preoperative OPPORTUNE study randomized patients to treatment with anastrozole \pm the pan-PI3K inhibitor pictisilib for 2 weeks before definitive surgery. The combination was significantly superior to anastrozole alone in suppressing Ki67. Luminal B gene expression but not presence of PIK3CA mutations in the diagnostic tumor biopsy was predictive of benefit from pictisilib (53). In metastatic breast cancer, the FERGI trial reported a longer progression free survival (PFS) with the combination of fulvestrant and pictisilib compared to fulvestrant (54), and the BELLE-2 trial showed an improvement in PFS in favor of fulvestrant and the pan-PI3K inhibitor buparlisib over fulvestrant in patients with PIK3CA mutations detected in plasma tumor DNA (54). It is difficult to make a case as to whether the results of OPPORTUNE correlate with results in the FERGI and BELLE-2 trials where, because of the toxicity of pictilisib and buparlisib, their rate of discontinuation and dose reduction was high. Two randomized neoadjuvant trials with PI3Ka inhibitors are in progress: Neo-ORB comparing letrozole \pm alpelisib, and LORELEI comparing letrozole \pm taselisib, both for 4-6 months and using clinical response and suppression of Ki67 as study endpoints. Both PI3Ka inhibitors are better tolerated and are being tested in parallel in large registration trials in patients with metastatic ER+ breast cancer. A scenario where the results from the metastatic trials with alpelisib and taselisib mirror those from their respective neoadjuvant trials would further support the value of the neoadjuvant platform for clinical trial prioritization. Neoadjuvant endocrine therapy trials using CDK4/6 and PI3K inhibitors are summarized in Table 3.

\section{Discovery of mechanisms of resistance to endocrine therapy}

Residual drug-resistant disease in the breast after neoadjuvant chemotherapy can be considered a surrogate for drug-resistant micrometastases that ultimately progress to clinically overt metastatic breast cancer. This paradigm has not been explored in ER+ breast cancer treated with NET. There are several reasons for this. First, there have been few NET trials with long term follow up where the post-treatment specimen has been profiled in any depth. Second, it is unclear whether after few months of NET, the residual cancer in the breast can be considered truly refractory to therapy. Third, it is also unclear if genomic changes induced by endocrine therapy are due to expansion of subpopulations of cells harboring resistant mutations or just fluctuation ('re-programing') in gene expression of existing cells, as suggested by studies exploring the effects of short term AIs (described below). Nonetheless, it is reasonable to speculate that a high Ki67 score and/or a high PEPIscore after NET may identify tumors with a high rate of recurrence where mechanisms and/or biomarkers of drug resistance can be interrogated using molecular methods. One of the earliest studies of 18 matched pairs of pre- and post-letrozole biopsies showed an enrichment of cells with tumor-initiating and mesenchymal gene expression signatures in the treated specimens (55), concordant with an enrichment in stem-like cells in triple negative tumors resistant to neoadjuvant chemotherapy (56), and the chemoresistance of letrozoleresistant tumors in ACOSOG Z1031B (26). Ellis and colleagues used whole genome 
sequencing (WGS) to interrogate 77 diagnostic biopsies of postmenopausal breast cancer patients that received neoadjuvant letrozole for 4-6 months (57). This study showed that tumors resistant to letrozole are more complex, with more structural variations and mutation rate than sensitive tumors, which could provide a source for emergence of mechanisms of endocrine resistance. $M A P 3 K 1$ mutations were associated with luminal A status, low-grade histology and low proliferation rates, whereas mutant TP53 was associated with poor prognostic features. Further, mutant GATA3 correlated with suppression of proliferation upon estrogen deprivation with letrozole.

The role of tumor heterogeneity on resistance to estrogen deprivation has been explored in two recent neoadjuvant studies. Miller et al. (58) used WGS and RNA-seq in $22 \mathrm{ER}+$ breast cancers before and after 4 months of treatment with an AI. These authors reported that ER+ breast cancers are clonally heterogeneous spatially, and also temporally, showing that the proportion of some of these clonal subpopulations markedly change upon treatment. Despite the relatively short treatment, several mutations were selected for or enriched after therapy, including two activating ESR1 mutations. In a second study, Gellert et al. (59) performed whole exome sequencing on baseline, surgical core-cuts and blood from 40 patients treated with an AI for 2 weeks. In resistant tumors where the Ki67 remained high, there were more somatic mutations than in good responders. Underscoring spatial heterogeneity, $30 \%$ of tumors contained subclones that were exclusive to the baseline (pre-treatment) or surgical cores (post-treatment), suggesting core biopsies in this setting provide limited tumor material and thus, cannot capture the complete molecular profiles of heterogeneous cancers. Further, TP53 mutations and a higher mutational load were associated with highly proliferative tumors that responded poorly to therapy.

\section{LIMITATIONS OF NEOADJUVANT ENDOCRINE THERAPY}

\section{Lack of well validated biomarkers}

Although on treatment Ki67 and PEPI score have shown utility in clinical investigation and discovery, they are not yet useful for individual patient care decisions. Assuming the framework proposed by Hayes et al. (60), a biomarker must demonstrate analytical and clinical validity and clinical utility before it can be used to guide treatment decisions.

Analytical validity, that is the ability of an assay to accurately and reliably measure the analyte of interest, is the first barrier to overcome. Visual interpretation of Ki67 staining has high intraobserver but low interobserver concordance $(61,62)$. The interobserver concordance is higher for low and high Ki67 values, which manifest the difficulty of establishing a cut-off on the intermediates Ki67 values for making clinical decisions. In order to decrease this variability, the International Ki67 Working Group has conducted several studies to analytically validate and standardize Ki67 evaluation across laboratories $(63,64)$, and recommended that an improved inter-observer reproducibility can be achieved on centrally stained tissue sections after training observers on a standardized visual scoring method. Another source of variability, which cannot be diminished through adoption of standard operating procedures, is intratumor heterogeneity of Ki67 levels $(65,66)$. Ki67 expression is usually higher in the tumor periphery than in the center, and some tumors show a diffuse pattern of Ki67 staining while some others show "hot" and "cold" spots. It is not 
clear whether there should focus on Ki67 "hot-spots" or whether the average Ki67 value is enough. These issues could be more prominent when estimating the proliferation rate in the whole tumor based on core-cut biopsies that usually represent a small fraction of the tumor mass. Because of these limitations, Denkert and colleagues suggested (67) that clinical decisions should not be based on Ki67 in intermediate cases. These patients would be ideal candidates for the use of gene expression signatures.

Despite the interobserver variance and tumor heterogeneity, the clinical validity of the Ki67 and PEPI-scores, that is their ability to distinguish patient populations with different outcomes is relatively established. Several studies have shown that Ki67 is able to classify tumors as endocrine resistant or sensitive. The fact that different studies show similar results, suggest that certain degree of variability in Ki67 assessment is admissible.

The clinical utility of the Ki67 and PEPI scores, that is their use for individual treatment decisions, is currently being evaluated in several studies. The first study to formally explore the clinical utility of on-treatment Ki67 values was ACOSOG Z1031B (26). In this study, patients with ER+ (Allred 6-8) breast cancer with a Ki67 $>10 \%$ after 2-4 weeks on an AI were defined as endocrine resistant and switched to any approved neoadjuvant chemotherapy regimen. Notably, these endocrine resistant tumors were also chemoresistant in that only 2 out of $35(5.7 \%)$ patients achieved a pCR. These results are intriguing and contrast with the reported $\sim 20 \%$ probability of pCR among highly proliferative ER+ tumors with a baseline Ki67 >35\% (68). On the other hand, patients in ACOSOG Z1031B whose tumors exhibited a Ki67 $\leq 10 \%$ at 2-4 weeks and remained on an aromatase inhibitor for 12-14 weeks had a PEPI-0 rate of $34 \%$, suggesting that early assessment of an on-treatment Ki67 score identifies highly hormone-dependent tumors where a recommendation of antiestrogen adjuvant therapy alone might be appropriate. Implementation of this approach will require additional investigation by incorporating the pharmacodynamic Ki67 data to other (steady state) genomic signatures currently utilized for adjuvant treatment recommendations.

Another study investigating the clinical utility of early assessment of Ki67 was the ADAPT HR+/HER2- (NCT01779206) trial (69). In this study, patients at diagnosis were assigned a risk category based on the OncotypeDX recurrence score (RS) and nodal status. A high risk group (N2-3, RS >26) received neoadjuvant chemotherapy. A low risk group (N0-1, RS $\leq 1$ ) received NET alone or surgery followed by adjuvant endocrine therapy. Patients with intermediate risk cancers (N0-1, RS 12-25) received endocrine therapy for 2 weeks; those with a 2-week Ki67 $₫ 0 \%$ stayed on endocrine therapy to complete 3 months, while patients with Ki67 $>10 \%$ were switched to chemotherapy. The hypothesis tested is that the 5-year RFS in the experimental group (N0-1, RS 12-25, 2-week Ki67 <10\%) treated with endocrine therapy alone will not be inferior to that of the low risk reference group (N0-1, RS 41). Herein, the on-treatment Ki67 is used to reduce overtreatment in an intermediate risk population with early signs of high sensitivity to antiestrogen therapy. This study is expecting to recruit 4,000 patients with ER+/HER2 negative breast cancer with estimation that $28 \%$ of patients will be classified as intermediate-risk with an early good response to NET. 
The POETIC study (NCT02338310) is designed to test the hypothesis that perioperative endocrine therapy can improve patient outcome. More than 4,000 postmenopausal patients with ER+ breast cancer are randomized to an AI or placebo for 2 weeks before and 2 weeks after surgery. A secondary objective is to test if the Ki67 score at 2 weeks is a better predictor of relapse-free survival than the pretreatment score. Although the adjuvant therapy it is not specified in the protocol, the large sample size of POETIC should allow some conclusions on the value of the 2-week Ki67 as predictor of patient outcome.

The clinical utility of PEPI score is also being evaluated in the ALTERNATE (NCT01953588) trial. This study is testing the hypothesis that patients with PEPI score 0 have a 5-year RFS $>95 \%$ with adjuvant endocrine therapy alone. The trial will also address whether fulvestrant either alone or in combination with anastrozole decreases the rate of endocrine resistance, defined as a Ki67 >10\% after 4-12 weeks of therapy or a modified PEPI score ( $T$, nodes and Ki67 without ER) other than 0. Those patients whose tumors exhibit a Ki67 $>10 \%$ at 4-12 weeks will be treated with neoadjuvant chemotherapy. Table 4 summarizes clinical trials investigating the clinical utility of Ki67 and PEPI scores. As this table shows, many ongoing studies include clinical overall response rate (ORR) as primary end-point, We recognize, however, that the validity of ORR using radiological methods, such as ultrasound, mammography or magnetic resonance imaging, as endpoint for the efficacy of NET trials has been limited (70). Further, ORR has failed to predict clinical outcome (71).

\section{Impact on long term outcome is difficult to measure}

Although the Ki67 and PEPI scores have shown preliminary validity as surrogate markers of long term outcome, it should be noted that this has been based on studies that used the same endocrine therapy in the neoadjuvant and adjuvant parts of the trial (IMPACT, P024, ACOSOG Z1031B). This limitation may also apply to other adjuvant cytostatic drugs, such as CDK4/6 inhibitors, where few months of neoadjuvant therapy would be insufficient to eliminate micrometastases. It is also unclear if Ki67 and/or the PEPI score would apply to other types of therapies. For example, if a combination induces tumor cell apoptosis, Ki67 would not be very useful in that setting. Thus, an effective approach to examine whether a novel neoadjuvant therapy against ER+ tumors impacts long term outcome would be to conduct two parallel trials: A neoadjuvant trial powered to see a difference in PEPI score and, second, a mirror image adjuvant trial powered to demonstrate an improvement in relapse-fee and/or overall survival.

\section{Biomarkers are unstable and/or insensitive}

Studies using a short term Ki67 score as an endpoint have the limitation that in a small fraction of tumors $(\sim 10 \%)$, drug-induced inhibition of proliferation is not sustained with the Ki67 rebounding at 12 weeks (25). These tumors may represent a group that quickly adapts to ER blockade and suggest that objective response criteria at 4-6 months, such as the PEPI score, should be more informative of the true effect of NET. Further, by integrating anatomic features such as tumor size and lymph node status, well validated independent prognostic factors in breast cancer, and incorporating data from surgical specimens instead of core biopsies, the PEPI score is less impacted by spatial intra-tumor heterogeneity and would be a more robust endpoint than Ki67 alone. 
Another pitfall of short term endpoints in NET is that they can be uninformative in low proliferating ER+ tumors. For example, for indolent tumors with a low pre-treatment Ki67 (i.e., 0-5\%), a treatment-induced change in the 2-week Ki67 may not be sensitive enough to provide a true reflection of the magnitude of drug action and the hormone dependence of the cancer. The limitation here is not the indolent biology of the tumors, which cannot be changed, but the crudeness of the insensitive assay. Thus, in these tumors other surrogates of antiestrogen action (i.e. PR levels, ER gene expression signatures, etc.) are needed for the detection of a pharmacodynamic drug effect, so they can be incorporated into NET trials.

\section{Inability to detect mechanisms of acquired resistance}

A common mechanism of acquired resistance to estrogen deprivation is the emergence of mutations in the ligand binding domain of ESR1. These mutations occur rarely in untreated primary breast cancer (72), but have a high prevalence in advanced breast cancers previously treated with AIs $(73,74)$ suggesting they occur as the result of treatment pressure and tumor evolution. Although the prevalence of ESR1 mutations is high in patients treated with an AI in the metastatic setting (10-35\%), it is low (0-5\%) in tumors sequenced at progression on adjuvant therapy (75). These data agree with the low incidence of ESR 1 mutations reported by Miller et al. (58), who sequenced $38 \mathrm{ER}+$ breast cancers after 4 months of neoadjuvant letrozole and found only two ESR 1 mutations. We should note that despite the plethora of NET trials, there are very few examples of deep molecular analysis of the post-treatment mastectomy specimens in these studies to investigate acquired or enriched for somatic alterations that may be causally associated with drug resistance. We anticipate, however, that with the increasing and eventually routine use of next gen sequencing of metastatic recurrences after standard of care antiestrogen therapy, both adjuvant and in the metastatic setting, more alterations associated with endocrine resistance that are not detected in the original breast tumor will be identified. Consistent with this prediction, a recent study conducted whole exome sequencing of 149 metastatic biopsies and 44 matched primary ER + tumors. There was a significant enrichment of mutations in ESR1, ERBB2, RB and $K R A S$, among others, in the metastases compared to the primary cancers (74).

\section{CONSIDERATIONS FOR CLINICAL TRIAL DESIGN}

\section{Patient selection}

It is well established that long term outcome after neoadjuvant vs. adjuvant chemotherapy is overall similar $(76,77)$. Since comparative studies of NET vs. 5 years of adjuvant endocrine therapy are not possible, it is difficult to prove the impact of NET on long term outcome. Thus, it is important not to include in these studies those patients with ER+ breast cancer with a likely superior curative option. These would include tumors with low ER content, N2-N3 status, very high baseline Ki67, and high histological grade where neoadjuvant chemotherapy is a more accepted option. For example, in patients with ER+/HER2- tumors and a baseline Ki67 >35\%, the rate of pCR with neoadjuvant chemotherapy is $\sim 20 \%$ but only $3 \%$ in those with a Ki67 score at baseline of $0-15 \%$ (68). Thus, it could be argued that NET in the former group could delay potentially curative therapy. For these high risk ER+ tumors treated with NET, an early assessment of efficacy after a short treatment interval 
would be indispensable to inform continuation of antiestrogen therapy vs. a change to another treatment.

\section{Classical NET vs enrichment adaptive NET trials}

In classical NET studies, such as IMPACT or P024, patients receive standard or investigational treatment for a period of 3-6 months before surgery. A biopsy for research purposes is incorporated at 2-3 weeks to assess drug-induced cellular activity in situ and/or pharmacodynamic biomarkers of drug action but there is no treatment modification at this time. Therefore, all patients with drug-sensitive and -resistant tumors receive the same treatment assigned at randomization. However, the prognostic ability of the early ontreatment Ki67 score - or another biomarker depending on the type of treatment - offers a tool to enrich the study with patients likely to benefit from the neoadjuvant approach and also to modify the treatment. Patients whose tumors do not suppress Ki67 are switched to an alternative therapy, i.e., chemotherapy or have a new drug added to the initial therapy. Patients whose tumors exhibit significant suppression of proliferation continue the original treatment until surgery and serve as control to the investigational arm (Figure 1A,B). This design enriches for drug 'resistant' tumors where benefit from a new drug over standard therapy can be interrogated.

\section{NET trials with a lead-in phase}

Recent trials, such as NEO-MONARCH or PALLET, have incorporated variations to the mainstream design of NET trials. These studies compared head to head endocrine therapy \pm a CDK4/6 inhibitor using the on-treatment Ki67 score at 2 weeks, with all patients receiving the combination up to 6 months (Figure 1C). In NEO-MONARCH, this approach showed marked cellular activity of single agent abemaciclib measured as a reduction in Ki67 (38), consistent with its clinical activity as monotherapy in patients with metastatic disease (43). Another 'lead-in' approach is illustrated by the multi-biopsy single arm trial of Ma et al (39). In this study, patients received anastrozole for 28 days, time at which a research biopsy is performed and the CDK4/6 inhibitor palbociclib was added. After 2 additional weeks of the combination, another biopsy was performed. Patients with cancers with a Ki67 $\geq 10 \%$ did not continue the study, while those with a Ki67<10\% continued treatment with the combination until surgery. By comparing Ki67 changes between the second biopsy (on anastrozole) and third biopsy (on anastrozole/palbociclib), this design evaluated the effect of CDK4/6 inhibition in patients where the aromatase inhibitor did not suppress tumor cell proliferation optimally, with each tumor serving as its own control (Figure 1D).

\section{Short presurgical vs neoadjuvant therapy trials}

Short presurgical trials (aka 'window' trials) are non-therapeutic studies in which patients are treated for 2-3 weeks immediately after their diagnostic biopsy and before breast surgery. Biomarkers of cellular activity (Ki67) and/or drug target modulation are measured in intraoperative biopsies and/or the surgical specimen. Since these studies do not have a therapeutic intent, patient safety and reasonable knowledge of the optimal drug dose are major considerations for this approach so delays and/or complications from surgery are avoided. In a review of 'window' trials in $>4,000$ patients and in all breast tumor types, there 
were only two deaths related to investigational drug and only $1 \%$ of patients could not undergo surgery due to adverse event (78).

Pharmacodynamic biomarkers and pharmacokinetics in this setting can provide additional knowledge of molecular mechanisms of action of a new agent or combination and also confirm molecular efficacy of the drug dose chosen. For biomarkers used for the first time, it would be appropriate to include a placebo control group to rule out drug-independent changes in such biomarker. Presurgical studies with SERMs (79), the EGFR/HER2 TKI lapatinib (80), and the CDK4/6 inhibitor (46) showed an overall 3-5\% change in Ki67 between pre- and on-treatment Ki67 in the placebo arm.

Short presurgical studies can also be used to test the performance of candidate predictive biomarkers. Examples would be use of PI3K inhibitors in PIK3CA mutant vs. PIK3CA wild tumors, FGFR inhibitors in tumors with or without somatic alterations in the FGFR pathway, or PARP inhibitors in tumors with or without a biomarker indicative of homologous repair deficiency. A difference between a biomarker-positive and -negative group would have important implications for patient selection in trials with the same drug(s) in metastatic disease. For example, if the new drug or combination exhibited clear 'activity', as defined by the 'window' study only in biomarker-positive tumors, this biomarker could be then used as a test predictive of clinical benefit in trials in patients with advanced cancer, where the drug indication will be initially pursued.

An integration of short presurgical and neoadjuvant therapeutic trials is depicted in Figure 2. Drugs with a strong preclinical background, documented safety and a recommended phase II dose undergo evaluation first through a so called 'window' trial. Therein, the (cellular) efficacy of the new drug or combination can be assessed by Ki67 suppression (or else depending on the mode of action of the therapy) and/or drug target modulation. If only biomarker-positive tumors show evidence of activity, strong consideration should be given to restricting neoadjuvant trials to only biomarker-positive tumors. If the presurgical phase involves a randomization and the investigational arm does not show an improvement over the control arm, such result should give pause to a similar neoadjuvant trial without additional modifications (i.e., patient selection based on a biomarker or another criteria). In other cases, the information gathered by the 'research' biopsy at 2-3 weeks can be used for triaging patients to a more established standard therapy, i.e., chemotherapy, or for progression into an adaptive neoadjuvant trial.

\section{Acknowledgments}

Supported by NIH Breast SPORE grant P50 CA098131, Vanderbilt-Ingram Cancer Center Support grant P30 CA68485, Susan G. Komen for the Cure Breast Cancer Research Foundation grant SAC100013, a grant from the Breast Cancer Research Foundation and a grant from the Spanish Society of Medical Oncology.

\section{References}

1. Pathological Complete Response in Neoadjuvant Treatment of High-Risk Early-Stage Breast Cancer: Use as an Endpoint to Support Accelerated Approval - ucm305501.pdf [Internet]. [cited 2016 Dec 12]. Available from: http://www.fda.gov/downloads/drugs/ guidancecomplianceregulatoryinformation/guidances/ucm305501.pdf 
2. Bradbeer JW, Kyngdon J. Primary treatment of breast cancer in elderly women with Tamoxifen. Clin Oncol. 1983; 9:31-4. [PubMed: 6851305]

3. Preece PE, Wood RA, Mackie CR, Cuschieri A. Tamoxifen as initial sole treatment of localised breast cancer in elderly women: a pilot study. Br Med J. 1982; 284:869-70.

4. Gaskell DJ, Hawkins RA, Sangsterl K, Chetty U, Forrest AP. Relation between immunocytochemical estimation of oestrogen receptor in elderly patients with primary breast cancer and response to tamoxifen. Lancet. 1989; 1:1044-6. [PubMed: 2566000]

5. Gaskell DJ, Hawkins RA, de Carteret S, Chetty U, Sangster K, Forrest AP. Indications for primary tamoxifen therapy in elderly women with breast cancer. Br J Surg. 1992; 79:1317-20. [PubMed: 1486428]

6. Morgan J, Wyld L, Collins KA, Reed MW. Surgery versus primary endocrine therapy for operable primary breast cancer in elderly women (70 years plus). Cochrane Database of Systematic Reviews. 2014:CD004272. pub3.

7. Morgan JL, Reed MW, Wyld L. Primary endocrine therapy as a treatment for older women with operable breast cancer - a comparison of randomised controlled trial and cohort study findings. Eur J Surg Oncol. 2014; 40:676-84. [PubMed: 24703110]

8. Spring LM, Gupta A, Reynolds KL, Gadd MA, Ellisen LW, Isakoff SJ, et al. Neoadjuvant Endocrine Therapy for Estrogen Receptor-Positive Breast Cancer: A Systematic Review and Meta-analysis. JAMA Oncol. 2016; 2:1477-86. [PubMed: 27367583]

9. Early Breast Cancer Trialists' Collaborative Group (EBCTCG). Comparisons between different polychemotherapy regimens for early breast cancer: meta-analyses of long-term outcome among 100000 women in 123 randomised trials. Lancet. 2012; 379:432-44. [PubMed: 22152853]

10. Cardoso F, van't Veer LJ, Bogaerts J, Slaets L, Viale G, Delaloge S, et al. 70-Gene Signature as an Aid to Treatment Decisions in Early-Stage Breast Cancer. N Engl J Med. 2016; 375:717-29. [PubMed: 27557300]

11. Sparano JA, Gray RJ, Makower DF, Pritchard KI, Albain KS, Hayes DF, et al. Prospective Validation of a 21-Gene Expression Assay in Breast Cancer. N Engl J Med. 2015; 373:2005-14. [PubMed: 26412349]

12. Alba E, Calvo L, Albanell J, De la Haba JR, Arcusa Lanza A, Chacon JI, et al. Chemotherapy (CT) and hormonotherapy (HT) as neoadjuvant treatment in luminal breast cancer patients: results from the GEICAM/2006-03, a multicenter, randomized, phase-II study. Ann Oncol. 2012; 23:3069-74. [PubMed: 22674146]

13. Semiglazov VF, Semiglazov VV, Dashyan GA, Ziltsova EK, Ivanov VG, Bozhok AA, et al. Phase 2 randomized trial of primary endocrine therapy versus chemotherapy in postmenopausal patients with estrogen receptor-positive breast cancer. Cancer. 2007; 110:244-54. [PubMed: 17538978]

14. Ueno T, Masuda N, Yamanaka T, Saji S, Kuroi K, Sato N, et al. Evaluating the 21-gene assay Recurrence Score ${ }^{\circledR}$ as a predictor of clinical response to 24 weeks of neoadjuvant exemestane in estrogen receptor-positive breast cancer. Int J Clin Oncol. 2014; 19:607-13. [PubMed: 24101215]

15. Dixon JM, Renshaw L, Macaskill EJ, Young O, Murray J, Cameron D, et al. Increase in response rate by prolonged treatment with neoadjuvant letrozole. Breast Cancer Res Treat. 2009; 113:14551. [PubMed: 18264759]

16. Llombart-Cussac A, Guerrero Á, Galán A, Carañana V, Buch E, Rodríguez-Lescure Á, et al. Phase II trial with letrozole to maximum response as primary systemic therapy in postmenopausal patients with ER/PgR[+] operable breast cancer. Clin Transl Oncol. 2012; 14:125-31. [PubMed: 22301401]

17. Carpenter R, Doughty JC, Cordiner C, Moss N, Gandhi A, Wilson C, et al. Optimum duration of neoadjuvant letrozole to permit breast conserving surgery. Breast Cancer Res Treat. 2014; 144:569-76. [PubMed: 24562823]

18. Chiba A, Hoskin TL, Heins CN, Hunt KK, Habermann EB, Boughey JC. Trends in Neoadjuvant Endocrine Therapy Use and Impact on Rates of Breast Conservation in Hormone ReceptorPositive Breast Cancer: A National Cancer Data Base Study. Ann Surg Oncol. 2017; 24:418-24. [PubMed: 27663568] 
19. von Minckwitz G, Untch M, Blohmer J-U, Costa SD, Eidtmann H, Fasching PA, et al. Definition and Impact of Pathologic Complete Response on Prognosis After Neoadjuvant Chemotherapy in Various Intrinsic Breast Cancer Subtypes. J Clin Oncol. 2012; 30:1796-804. [PubMed: 22508812]

20. Cortazar P, Zhang L, Untch M, Mehta K, Costantino JP, Wolmark N, et al. Pathological complete response and long-term clinical benefit in breast cancer: the CTNeoBC pooled analysis. Lancet. 2014; 384:164-72. [PubMed: 24529560]

21. Mackay A, Urruticoechea A, Dixon JM, Dexter T, Fenwick K, Ashworth A, et al. Molecular response to aromatase inhibitor treatment in primary breast cancer. Breast Cancer Res. 2007; 9:R37. [PubMed: 17555561]

22. Ellis MJ, Coop A, Singh B, Tao Y, Llombart-Cussac A, Jänicke F, et al. Letrozole Inhibits Tumor Proliferation More Effectively than Tamoxifen Independent of HER1/2 Expression Status. Cancer Res. 2003; 63:6523-31. [PubMed: 14559846]

23. Zoubir M, Mathieu MC, Mazouni C, Liedtke C, Corley L, Geha S, et al. Modulation of ER phosphorylation on serine 118 by endocrine therapy: a new surrogate marker for efficacy. Ann Oncol. 2008; 19:1402-6. [PubMed: 18436523]

24. Urruticoechea A, Smith IE, Dowsett M. Proliferation marker Ki-67 in early breast cancer. J Clin Oncol. 2005; 23:7212-20. [PubMed: 16192605]

25. Dowsett M, Smith IE, Ebbs SR, Dixon JM, Skene A, Griffith C, et al. Short-Term Changes in Ki-67 during Neoadjuvant Treatment of Primary Breast Cancer with Anastrozole or Tamoxifen Alone or Combined Correlate with Recurrence-Free Survival. Clin Cancer Res. 2005; 11:951s958s. [PubMed: 15701892]

26. Ellis MJ, Suman VJ, Hoog J, Goncalves R, Sanati S, Creighton CJ, et al. Ki67 Proliferation Index as a Tool for Chemotherapy Decisions During and After Neoadjuvant Aromatase Inhibitor Treatment of Breast Cancer: Results From the American College of Surgeons Oncology Group Z1031 Trial (Alliance). J Clin Oncol. 2017 Jan 3. Epub ahead of print.

27. Dowsett M, Smith IE, Ebbs SR, Dixon JM, Skene A, A’Hern R, et al. Prognostic Value of Ki67 Expression After Short-Term Presurgical Endocrine Therapy for Primary Breast Cancer. J Natl Cancer Inst. 2007; 99:167-70. [PubMed: 17228000]

28. Ellis MJ, Tao Y, Luo J, A’Hern R, Evans DB, Bhatnagar AS, et al. Outcome prediction for estrogen receptor-positive breast cancer based on postNET tumor characteristics. J Natl Cancer Inst. 2008; 100:1380-8. [PubMed: 18812550]

29. Ellis MJ, Luo J, Tao Y, et al. Tumor Ki67 proliferation index within 4 weeks of initiating NET for early identification of non-responders. Presented at: 2009 San Antonio Breast Cancer Symposium. Abstract. 78

30. Ellis MJ, Suman VJ, Hoog J, Lin L, Snider J, Prat A, et al. Randomized phase II neoadjuvant comparison between letrozole, anastrozole, and exemestane for postmenopausal women with estrogen receptor-rich stage 2 to 3 breast cancer: clinical and biomarker outcomes and predictive value of the baseline PAM50-based intrinsic subtype-ACOSOG Z1031. J Clin Oncol. 2011; 29:2342-9. [PubMed: 21555689]

31. Symmans WF, Peintinger F, Hatzis C, Rajan R, Kuerer H, Valero V, et al. Measurement of residual breast cancer burden to predict survival after neoadjuvant chemotherapy. J Clin Oncol. 2007; 25:4414-22. [PubMed: 17785706]

32. Peintinger F, Sinn B, Hatzis C, Albarracin C, Downs-Kelly E, Morkowski J, et al. Reproducibility of residual cancer burden for prognostic assessment of breast cancer after neoadjuvant chemotherapy. Mod Pathol. 2015; 28:913-20. [PubMed: 25932963]

33. Sheri A, Smith IE, Johnston SR, A'Hern R, Nerurkar A, Jones RL, et al. Residual proliferative cancer burden to predict long-term outcome following neoadjuvant chemotherapy. Ann Oncol. 2015; 26:75-80. [PubMed: 25361988]

34. Baum M, Budzar AU, Cuzick J, Forbes J, Houghton JH, Klijn JGM, et al. Anastrozole alone or in combination with tamoxifen versus tamoxifen alone for adjuvant treatment of postmenopausal women with early breast cancer: first results of the ATAC randomised trial. Lancet. 2002; 359:2131-9. [PubMed: 12090977] 
35. Breast International Group (BIG) 1-98 Collaborative Group. Thürlimann B, Keshaviah A, Coates AS, Mouridsen H, Mauriac L, et al. A comparison of letrozole and tamoxifen in postmenopausal women with early breast cancer. N Engl J Med. 2005; 353:2747-57. [PubMed: 16382061]

36. Goss PE, Ingle JN, Pritchard KI, Ellis MJ, Sledge GW, Budd GT, et al. Exemestane versus anastrozole in postmenopausal women with early breast cancer: NCIC CTG MA.27-a randomized controlled phase III trial. J Clin Oncol. 2013; 31:1398-404. [PubMed: 23358971]

37. Smith I, Yardley D, Burris H, De Boer R, Amadori D, McIntyre K, et al. Comparative Efficacy and Safety of Adjuvant Letrozole Versus Anastrozole in Postmenopausal Patients With Hormone Receptor-Positive, Node-Positive Early Breast Cancer: Final Results of the Randomized Phase III Femara Versus Anastrozole Clinical Evaluation (FACE) Trial. J Clin Oncol. 2017 Jan 23. Epub ahead of print.

38. Hurvitz SA, Schilder JM, Frenzel M, Martín M. Abstract CT092: A phase II study of neoadjuvant abemaciclib (LY2835219) in postmenopausal women with hormone receptor positive (HR+), human epidermal growth factor receptor 2 negative (HER2-) breast cancer (neoMONARCH). Cancer Res. 2016; 76:CT092-CT092.

39. Ma CX, Gao F, Northfelt D, Goetz M, Forero A, Naughton M, et al. Abstract S6-05: A phase II trial of neoadjuvant palbociclib, a cyclin-dependent kinase (CDK) 4/6 inhibitor, in combination with anastrozole for clinical stage 2 or 3 estrogen receptor positive HER2 negative (ER+HER2-) breast cancer (BC). Cancer Res. 2016; 76:S6-05-S6-05.

40. Hortobagyi GN, Stemmer SM, Burris HA, Yap Y-S, Sonke GS, Paluch-Shimon S, et al. Ribociclib as First-Line Therapy for HR-Positive, Advanced Breast Cancer. N Engl J Med. 2016; 375:173848. [PubMed: 27717303]

41. Finn RS, Martin M, Rugo HS, Jones S, Im S-A, Gelmon K, et al. Palbociclib and Letrozole in Advanced Breast Cancer. N Engl J Med. 2016; 375:1925-36. [PubMed: 27959613]

42. Cristofanilli M, Turner NC, Bondarenko I, Ro J, Im S-A, Masuda N, et al. Fulvestrant plus palbociclib versus fulvestrant plus placebo for treatment of hormone-receptor-positive, HER2negative metastatic breast cancer that progressed on previous endocrine therapy (PALOMA-3): final analysis of the multicentre, double-blind, phase 3 randomised controlled trial. Lancet Oncol. 2016; 17:425-39. [PubMed: 26947331]

43. Dickler, MN., Tolaney, SM., Rugo, HS., Cortes, J., Dieras, V., Patt, DA., Wildiers, H., Frenzel, M., Koustenis, A., Baselga, J. MONARCH1: Results from a phase II study of abemaciclib, a CDK4 and CDK6 inhibitor, as monotherapy, in patients with HR+/HER2- breast cancer, after chemotherapy for advanced disease; Proceedings of the 2016 ASCO Annual Meeting; Chicago IL, USA. 3-7 June 2016;

44. Kuter I, Gee JMW, Hegg R, Singer CF, Badwe RA, Lowe ES, et al. Dose-dependent change in biomarkers during NET with fulvestrant: results from NEWEST, a randomized Phase II study. Breast Cancer Res Treat. 2012; 133:237-46. [PubMed: 22286314]

45. Di Leo A, Jerusalem G, Petruzelka L, Torres R, Bondarenko IN, Khasanov R, Verhoeven D, Pedrini JL, Smirnova I, Lichinitser MR, Pendergrass K, Malorni L, Garnett S, et al. Final overall survival: fulvestrant $500 \mathrm{mg}$ vs $250 \mathrm{mg}$ in the randomized CONFIRM trial. J Natl Cancer Inst. 2014; 106:djt337. [PubMed: 24317176]

46. Arnedos M, Cheaib B, Bayar MA, Michiels S, Scott V, Adam J, et al. Abstract CT041: Antiproliferative response and predictive biomarkers to palbociclib in early breast cancer: The Preoperative Palbociclib (POP) randomized trial. Cancer Res. 2016; 76:CT041-CT041.

47. Dowling RJO, Niraula S, Chang MC, Done SJ, Ennis M, McCready DR, et al. Changes in insulin receptor signaling underlie neoadjuvant metformin administration in breast cancer: a prospective window of opportunity neoadjuvant study. Breast Cancer Res. 2015; 17:32. [PubMed: 25849721]

48. Hadad SM, Coates P, Jordan LB, Dowling RJO, Chang MC, Done SJ, et al. Evidence for biological effects of metformin in operable breast cancer: biomarker analysis in a pre-operative window of opportunity randomized trial. Breast Cancer Res Treat. 2015; 150:149-55. [PubMed: 25682077]

49. Smith IE, Walsh G, Skene A, Llombart A, Mayordomo JI, Detre S, et al. A phase II placebocontrolled trial of neoadjuvant anastrozole alone or with gefitinib in early breast cancer. J Clin Oncol. 2007; 25:3816-22. [PubMed: 17679728]

50. Cristofanilli M, Valero V, Mangalik A, Royce M, Rabinowitz I, Arena FP, et al. Phase II, randomized trial to compare anastrozole combined with gefitinib or placebo in postmenopausal 
women with hormone receptor-positive metastatic breast cancer. Clin Cancer Res. 2010; 16:190414. [PubMed: 20215537]

51. Osborne CK, Neven P, Dirix LY, Mackey JR, Robert J, Underhill C, et al. Gefitinib or placebo in combination with tamoxifen in patients with hormone receptor-positive metastatic breast cancer: a randomized phase II study. Clin Cancer Res. 2011; 17:1147-59. [PubMed: 21220480]

52. Johnston S, Basik M, Hegg R, Lausoontornsiri W, Grzeda L, Clemons M, et al. Inhibition of EGFR, HER2, and HER3 signaling with AZD8931 in combination with anastrozole as an anticancer approach: Phase II randomized study in women with endocrine-therapy-naïve advanced breast cancer. Breast Cancer Res Treat. 2016; 160:91-9. [PubMed: 27654971]

53. Schmid P, Pinder SE, Wheatley D, Macaskill J, Zammit C, Hu J, et al. Phase II Randomized Preoperative Window-of-Opportunity Study of the PI3K Inhibitor Pictilisib Plus Anastrozole Compared With Anastrozole Alone in Patients With Estrogen Receptor-Positive Breast Cancer. J Clin Oncol. 2016; 34:1987-94. [PubMed: 26976426]

54. Krop IE, Mayer IA, Ganju V, Dickler M, Johnston S, Morales S, et al. Pictilisib for oestrogen receptor-positive, aromatase inhibitor-resistant, advanced or metastatic breast cancer (FERGI): a randomised, double-blind, placebo-controlled, phase 2 trial. Lancet Oncol. 2016; 17:811-21. [PubMed: 27155741]

55. Creighton CJ, Li X, Landis M, Dixon JM, Neumeister VM, Sjolund A, et al. Residual breast cancers after conventional therapy display mesenchymal as well as tumor-initiating features. Proc Natl Acad Sci USA. 2009; 106:13820-5. [PubMed: 19666588]

56. Bhola NE, Balko JM, Dugger TC, Kuba MG, Sánchez V, Sanders M, et al. TGF- $\beta$ inhibition enhances chemotherapy action against triple-negative breast cancer. J Clin Invest. 2013; 123:134858. [PubMed: 23391723]

57. Ellis MJ, Ding L, Shen D, Luo J, Suman VJ, Wallis JW, et al. Whole-genome analysis informs breast cancer response to aromatase inhibition. Nature. 2012; 486:353-60. [PubMed: 22722193]

58. Miller CA, Gindin Y, Lu C, Griffith OL, Griffith M, Shen D, et al. Aromatase inhibition remodels the clonal architecture of estrogen-receptor-positive breast cancers. Nat Commun. 2016; 7:12498. [PubMed: 27502118]

59. Gellert P, Segal CV, Gao Q, López-Knowles E, Martin L-A, Dodson A, et al. Impact of mutational profiles on response of primary oestrogen receptor-positive breast cancers to oestrogen deprivation. Nat Commun. 2016; 7:13294. [PubMed: 27827358]

60. Hayes DF, Bast RC, Desch CE, Fritsche H, Kemeny NE, Jessup JM, et al. Tumor marker utility grading system: a framework to evaluate clinical utility of tumor markers. J Natl Cancer Inst. 1996; 88:1456-66. [PubMed: 8841020]

61. Polley M-YC, Leung SCY, McShane LM, Gao D, Hugh JC, Mastropasqua MG, et al. An International Ki67 Reproducibility Study. J Natl Cancer Inst. 2013; 105:1897-906. [PubMed: 24203987]

62. Mikami Y, Ueno T, Yoshimura K, Tsuda H, Kurosumi M, Masuda S, et al. Interobserver concordance of Ki67 labeling index in breast cancer: Japan Breast Cancer Research Group Ki67 ring study. Cancer Sci. 2013; 104:1539-43. [PubMed: 23905924]

63. Polley M-YC, Leung SCY, Gao D, Mastropasqua MG, Zabaglo LA, Bartlett JMS, et al. An international study to increase concordance in Ki67 scoring. Mod Pathol. 2015; 28:778-86. [PubMed: 25698062]

64. Leung SCY, Nielsen TO, Zabaglo L, Arun I, Badve SS, Bane AL, et al. Analytical validation of a standardized scoring protocol for Ki67: phase 3 of an international multicenter collaboration. npj Breast Cancer. 2016; 2:16014.

65. Focke CM, Decker T, van Diest PJ. Intratumoral heterogeneity of Ki67 expression in early breast cancers exceeds variability between individual tumours. Histopathology. 2016; 69:849-61. [PubMed: 27270560]

66. Himuro T, Horimoto Y, Arakawa A, Tanabe M, Saito M. Ki67 Heterogeneity in Estrogen ReceptorPositive Breast Cancers: Which Tumor Type Has the Most Heterogeneity? Int J Surg Pathol. 2016; 24:103-7. [PubMed: 26353854] 
67. Denkert C, Budczies J, von Minckwitz G, Wienert S, Loibl S, Klauschen F. Strategies for developing Ki67 as a useful biomarker in breast cancer. The Breast. 2015; 24(Supplement 2):S6772. [PubMed: 26283598]

68. Denkert C, Loibl S, Müller BM, Eidtmann H, Schmitt WD, Eiermann W, et al. Ki67 levels as predictive and prognostic parameters in pretherapeutic breast cancer core biopsies: a translational investigation in the neoadjuvant GeparTrio trial. Ann Oncol. 2013; 24:2786-93. [PubMed: 23970015]

69. Hofmann D, Nitz U, Gluz O, Kates RE, Schinkoethe T, Staib P, et al. WSG ADAPT - adjuvant dynamic marker-adjusted personalized therapy trial optimizing risk assessment and therapy response prediction in early breast cancer: study protocol for a prospective, multi-center, controlled, non-blinded, randomized, investigator initiated phase II/III trial. Trials. 2013; 14:261. [PubMed: 23958221]

70. Semiglazov V. RECIST for Response (Clinical and Imaging) in Neoadjuvant Clinical Trials in Operable Breast Cancer. J Natl Cancer Inst Monogr. 2015; 2015:21-3. [PubMed: 26063880]

71. Smith IE, Dowsett M, Ebbs SR, Dixon JM, Skene A, Blohmer J-U, et al. Neoadjuvant treatment of postmenopausal breast cancer with anastrozole, tamoxifen, or both in combination: the Immediate Preoperative Anastrozole, Tamoxifen, or Combined with Tamoxifen (IMPACT) multicenter double-blind randomized trial. J Clin Oncol. 2005; 23:5108-16. [PubMed: 15998903]

72. Cancer Genome Atlas Network. Comprehensive molecular portraits of human breast tumours. Nature. 2012; 490:61-70. [PubMed: 23000897]

73. Toy W, Weir H, Razavi P, Lawson M, Goeppert AU, Mazzola AM, et al. Activating ESR1 Mutations Differentially Impact the Efficacy of ER Antagonists. Cancer Discov. 2016 Dec 16. Epub ahead of print.

74. Cohen, O., Kim, D., Oh, C., Buendia, J., et al. Whole exome and transcriptome sequencing of resistant ER+ metastatic breast cancer; Presented at: 2016 San Antonio Breast Cancer Symposium; December 6-10; San Antonio, TX. Abstract S1-01

75. Schiavon G, Hrebien S, Garcia-Murillas I, Cutts RJ, Pearson A, Tarazona N, et al. Analysis of ESR1 mutation in circulating tumor DNA demonstrates evolution during therapy for metastatic breast cancer. Sci Transl Med. 2015; 7:313ra182.

76. Rastogi P, Anderson SJ, Bear HD, Geyer CE, Kahlenberg MS, Robidoux A, et al. Preoperative chemotherapy: updates of National Surgical Adjuvant Breast and Bowel Project Protocols B-18 and B-27. J Clin Oncol. 2008; 26:778-85. [PubMed: 18258986]

77. Mauri D, Pavlidis N, Ioannidis JPA. Neoadjuvant Versus Adjuvant Systemic Treatment in Breast Cancer: A Meta-Analysis. J Natl Cancer Inst. 2005; 97:188-94. [PubMed: 15687361]

78. Marous M, Bièche I, Paoletti X, Alt M, Razak ARA, Stathis A, et al. Designs of preoperative biomarkers trials in oncology: a systematic review of the literature. Ann Oncol. 2015; 26:2419-28. [PubMed: 26371283]

79. Serrano D, Lazzeroni M, Gandini S, Macis D, Johansson H, Gjerde J, et al. A randomized phase II presurgical trial of weekly low-dose tamoxifen versus raloxifene versus placebo in premenopausal women with estrogen receptor-positive breast cancer. Breast Cancer Research. 2013; 15:R47. [PubMed: 23786776]

80. Leary A, Evans A, Johnston SRD, A'Hern R, Bliss JM, Sahoo R, et al. Antiproliferative Effect of Lapatinib in HER2-Positive and HER2-Negative/HER3-High Breast Cancer: Results of the Presurgical Randomized MAPLE Trial (CRUK E/06/039). Clin Cancer Res. 2015; 21:2932-40. [PubMed: 25398453]

81. Masuda N, Sagara Y, Kinoshita T, Iwata H, Nakamura S, Yanagita Y, et al. Neoadjuvant anastrozole versus tamoxifen in patients receiving goserelin for premenopausal breast cancer (STAGE): a double-blind, randomised phase 3 trial. Lancet Oncol. 2012; 13:345-52. [PubMed: 22265697]

82. Pagani O, Regan MM, Walley BA, Fleming GF, Colleoni M, Láng I, et al. Adjuvant exemestane with ovarian suppression in premenopausal breast cancer. N Engl J Med. 2014; 371:107-18. [PubMed: 24881463]

83. Baselga J, Semiglazov V, van Dam P, Manikhas A, Bellet M, Mayordomo J, et al. Phase II randomized study of neoadjuvant everolimus plus letrozole compared with placebo plus letrozole 
in patients with estrogen receptor-positive breast cancer. J Clin Oncol. 2009; 27:2630-7. [PubMed: 19380449]

84. Baselga J, Campone M, Piccart M, Burris HA, Rugo HS, Sahmoud T, et al. Everolimus in postmenopausal hormone-receptor-positive advanced breast cancer. N Engl J Med. 2012; 366:5209. [PubMed: 22149876]

85. Tryfonidis K, Basaran G, Bogaerts J, Debled M, Dirix L, Thery J-C, et al. A European Organisation for Research and Treatment of Cancer randomized, double-blind, placebo-controlled, multicentre phase II trial of anastrozole in combination with gefitinib or placebo in hormone receptor-positive advanced breast cancer (NCT00066378). European Journal of Cancer. 2016; 53:144-54. [PubMed: 26724641]

86. Guarneri V, Generali DG, Frassoldati A, Artioli F, Boni C, Cavanna L, et al. Double-Blind, Placebo-Controlled, Multicenter, Randomized, Phase IIB Neoadjuvant Study of LetrozoleLapatinib in Postmenopausal Hormone Receptor-Positive, Human Epidermal Growth Factor Receptor 2-Negative, Operable Breast Cancer. J Clin Oncol. 2014; 32:1050-7. [PubMed: 24590635]

87. Johnston S, Pippen J, Pivot X, Lichinitser M, Sadeghi S, Dieras V, et al. Lapatinib combined with letrozole versus letrozole and placebo as first-line therapy for postmenopausal hormone receptorpositive metastatic breast cancer. J Clin Oncol. 2009; 27:5538-46. [PubMed: 19786658]

88. Curigliano G, Gómez Pardo P, Meric-Bernstam F, Conte P, Lolkema MP, Beck JT, et al. Ribociclib plus letrozole in early breast cancer: A presurgical, window-of-opportunity study. Breast. 2016; 28:191-8. [PubMed: 27336726] 


\section{STATEMENT OF SIGNIFICANCE}

Neoadjuvant endocrine therapy is an excellent platform for development of investigational drugs, triaging of novel combinations, biomarker validation, and discovery of mechanisms of drug resistance. This review summarizes the clinical and investigational benefit of this approach, with a focus on how to best integrate predictive biomarkers into novel clinical trial designs. 


\section{SUMMARY}

Neoadjuvant endocrine therapy not only offers clinical benefit to select patients with early ER+ breast cancer, but also provides an excellent platform for development of investigational drugs, triaging of novel combinations, biomarker validation, and discovery of mechanisms of drug resistance. A number of examples already suggest that knowledge gained from NET studies provides information to predict if a new combination is likely to be successful in large adjuvant or metastatic phase III trials. We anticipate an increasing use of this clinical platform in the near future which, in turn, may help focusing the development of drugs with an accelerated pathway to approval for use in patients with ER+ breast cancer. 
A: Classical

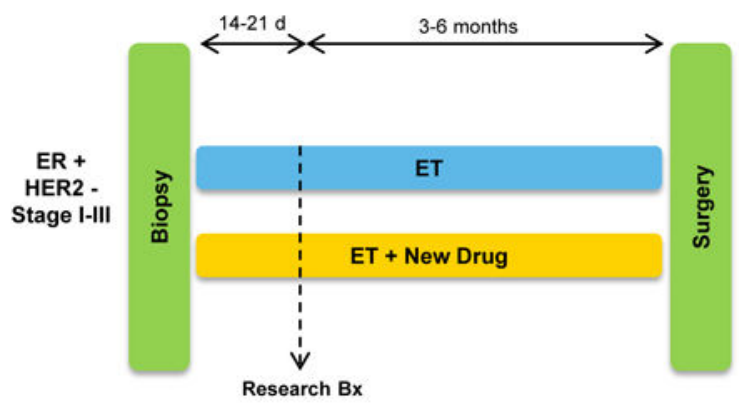

C: Multi Arm Lead-in Phase

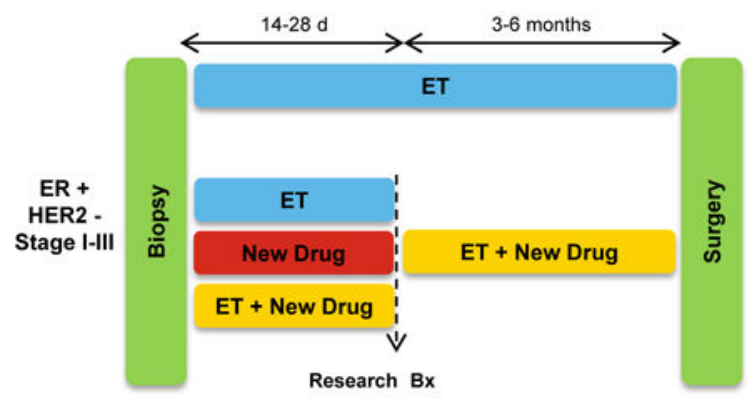

B: Enrichment Adaptive Design

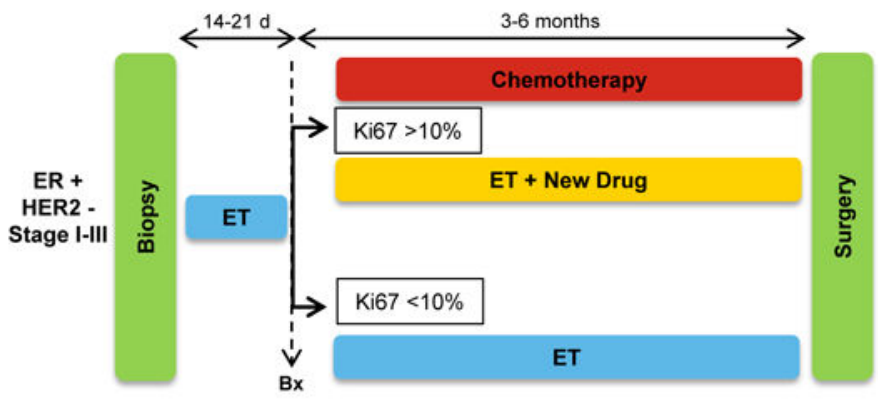

D: Single Arm Multiple Biopsies

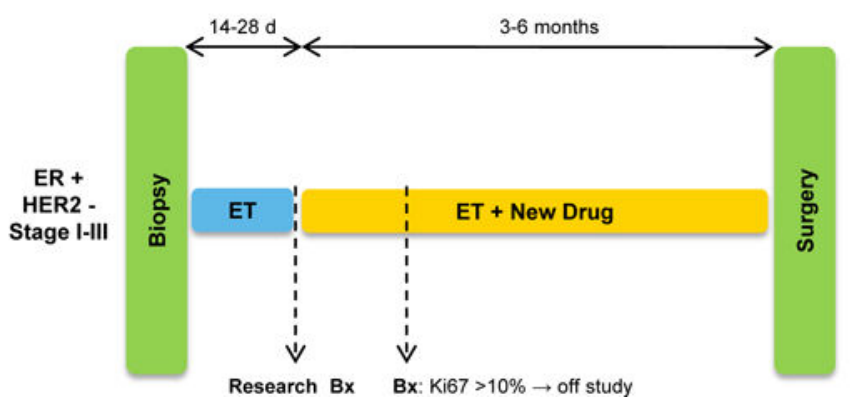

Figure 1.

Different designs of NET trials (NET) trials in ER+/HER- breast cancer. A: Classical NET trial; patients receive the assigned therapy for the 3-6 months before surgery without any treatment modification; an on-treatment research biopsy is performed after 2-3 weeks. B: Enrichment Adaptive Design NET trial; patients receive endocrine therapy (ET) for 2-3 weeks and those patients whose tumors do not suppress Ki67 below a pre-established threshold are switched to chemotherapy or to the addition of a new drug, while those showing significant suppression of Ki67 continue on ET alone. C: Multi Arm Lead-in Phase NET trial; head to head comparison of ET \pm a new drug using the on-treatment 2-week Ki67 score as endpoint. Afterwards all patients receive ET + the investigational drug for 4-6 months before surgery. D: Single Arm Multiple Biopsies NET trial; patients receive ET for 2-4 weeks, time at which a research biopsy is performed and an investigational drug is added. After 2 additional weeks another biopsy is performed. Patients with cancers with a Ki67 $\geq 10 \%$ do not continue on study, while those with a Ki67<10\% continue treatment with the combination until surgery. 


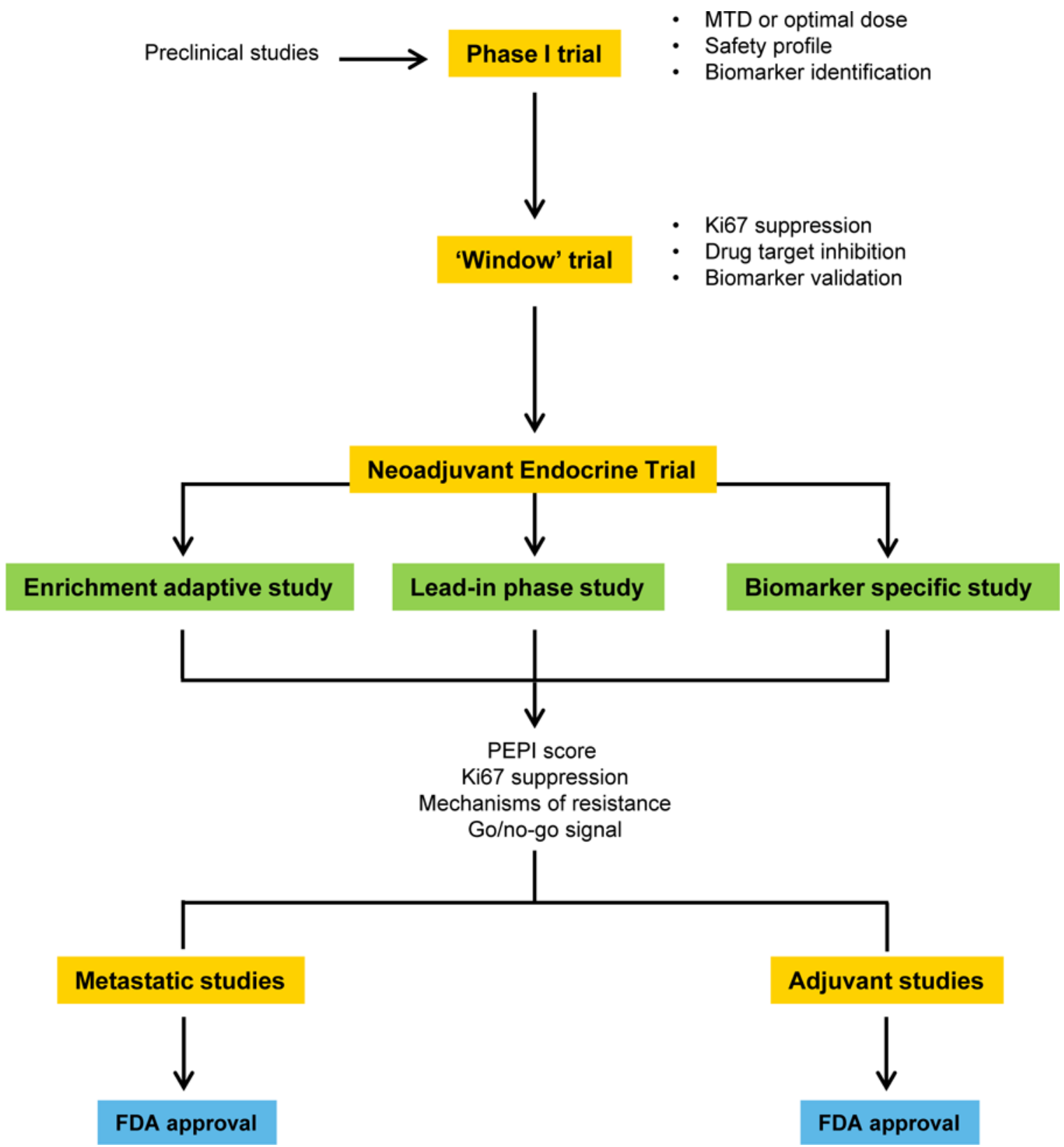

Figure 2.

Model for integration of short presurgical and NET trials in patients with early operable ER +/HER2- breast cancer. 


\section{Table 1}

Benefits of Neoadjuvant Endocrine Therapy

Avoidance of surgery in frail/older patients

Alternative to neoadjuvant chemotherapy in selected patients

Breast conserving surgery

Provide prognostic information

Confirmation of drug target inhibition

Validation of biomarker predictive of response

Go vs. no-go signal for large adjuvant trials

Triaging of combinations to be tested in metastatic disease

Discovery of mechanisms of drug resistance 


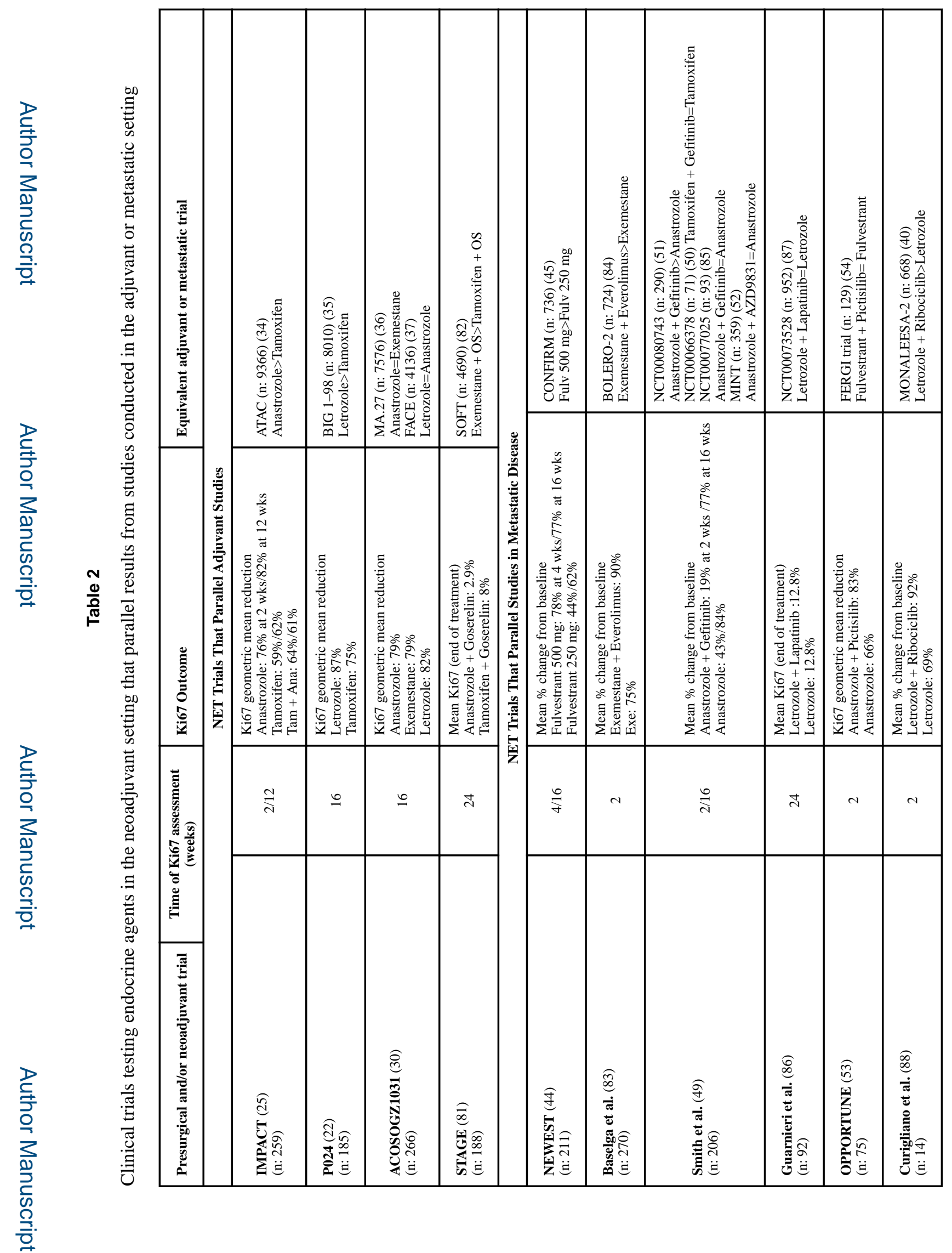

Cancer Discov. Author manuscript; available in PMC 2018 June 01. 


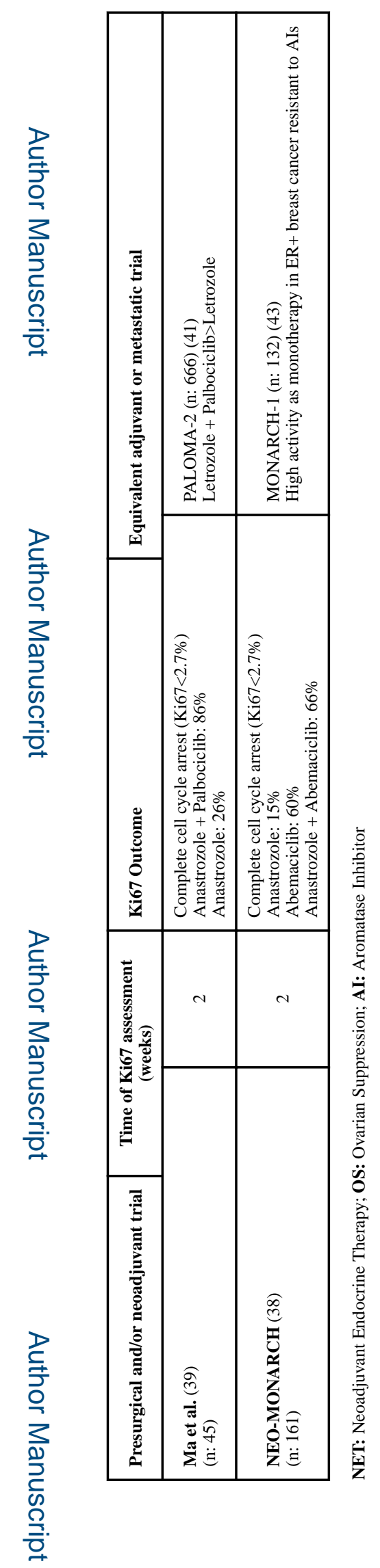

Cancer Discov. Author manuscript; available in PMC 2018 June 01. 
Table 3

Current Randomized Neoadjuvant Endocrine Therapy Trials

\begin{tabular}{|c|c|c|c|}
\hline Trial & Profile & Treatment & Primary Endpoint(s) \\
\hline \multicolumn{4}{|c|}{ With PI3K inhibitors } \\
\hline $\begin{array}{c}\text { NCT01923168 } \\
\text { NEO-ORB }\end{array}$ & $\begin{array}{l}\text { Phase II (n: } 360) \\
\text { T1-3 } \\
\text { Stratification: } \\
P I K 3 C A \text { mut: Ki67 low vs high } \\
P I K 3 C A \text { wt: Ki67 low vs high }\end{array}$ & $\begin{array}{l}\quad 6 \text { months } \\
\text { A: Letrozole + Placebo } \\
\text { B: Letrozole + Alpelisib } \\
\text { C: Letrozole + Buparlisib }\end{array}$ & $\mathrm{pCR}$ \\
\hline $\begin{array}{c}\text { NCT02273973 } \\
\text { LORELEI }\end{array}$ & $\begin{array}{l}\text { Phase II (n: } 330) \\
\text { Stage I-III } \\
\mathrm{T}>2 \mathrm{~cm} \text { by MRI } \\
\text { Available PIK3CA mut status }\end{array}$ & $\begin{array}{l}\quad 4 \text { months } \\
\text { A: Letrozole + Placebo } \\
\text { B: Letrozole + Taselisib }\end{array}$ & $\begin{array}{l}\text { 1. pCR } \\
\text { 2. OR by MRI }\end{array}$ \\
\hline \multicolumn{4}{|c|}{ With CDK4/6 inhibitors } \\
\hline $\begin{array}{l}\text { NCT02712723 } \\
\text { FELINI }\end{array}$ & $\begin{array}{l}\text { Phase II (n: 120) } \\
\text { Stage II-III } \\
\text { ER Allred: } 6-8\end{array}$ & $\begin{array}{l}\quad 6 \text { months } \\
\text { A: Letrozole + Placebo } \\
\text { B: Letrozole + Ribociclib }\end{array}$ & PEPI 0 \\
\hline $\begin{array}{l}\text { NCT02296801 } \\
\text { PALLET }\end{array}$ & $\begin{array}{l}\text { Phase II (n: 306) } \\
T>2 \mathrm{~cm}\end{array}$ & $\begin{array}{l}\mathbf{2} \text { weeks } \rightarrow \mathbf{3} \text { months } \\
\text { A: Letrozole }+ \text { Placebo } \\
\text { B: Let } \rightarrow \text { Let }+ \text { Palbociclib } \\
\text { C: Palbociclib } \rightarrow \text { Let }+ \text { Palbociclib } \\
\text { D: Let }+ \text { Palbociclib } \rightarrow \text { Let }+ \text { Palbociclib }\end{array}$ & Ki67 at 2 wks \\
\hline $\begin{array}{l}\text { NCT02764541 } \\
\text { PELOPS }\end{array}$ & $\begin{array}{l}\text { Phase II (n: 180) } \\
\text { Stage I-III } \\
\text { Invasive Lobular Cancer }\end{array}$ & $\begin{array}{l}\mathbf{2} \text { weeks } \rightarrow \mathbf{6} \text { months } \\
\text { A: Tamoxifen } \\
\text { B: Letrozole } \\
\text { C: Tam } \rightarrow \text { Tam + Palbociclib } \\
\text { D: Let } \rightarrow \text { Let + Palbociclib }\end{array}$ & $\begin{array}{l}\text { 1. } \mathrm{pCR} \\
\text { 2. Ki67 at } 2 \mathrm{wks} \\
\text { 3. RCB } 0-1\end{array}$ \\
\hline $\begin{array}{l}\text { NCT02400567 } \\
\text { NEOPAL }\end{array}$ & $\begin{array}{l}\text { Phase II (n: 132) } \\
\text { Stage II-III } \\
\text { ER Allred }>4 \\
\text { PAM50 Luminal B or Lum A/N1 }\end{array}$ & $\begin{array}{l}5 \text { months } \\
\text { A: FEC x } 3 \rightarrow \text { Docetaxel x3 } \\
\text { B: Letrozole + Palbociclib }\end{array}$ & RCB 0-1 \\
\hline NCT02441946 NEO-MONARCH & $\begin{array}{l}\text { Phase II (n: 148) } \\
\mathrm{T}>1 \mathrm{~cm} \\
\mathrm{Ki} 67>5 \%\end{array}$ & $\begin{array}{l}\mathbf{2} \text { weeks } \rightarrow \mathbf{4} \text { months } \\
\mathrm{A}: \text { Anastrozole } \rightarrow \text { Ana }+ \text { Abemaciclib } \\
\mathrm{B}: \text { Ana }+\mathrm{Abema} \rightarrow \text { Ana }+ \text { Abema } \\
\mathrm{C}: \text { Abema } \rightarrow \text { Ana }+ \text { Abema }\end{array}$ & Ki67 at 2 wks \\
\hline
\end{tabular}

pCR: Pathologic Complete Response; OR:Objective Response; MRI: Magnetic Resonance Imaging; RCB: Residual Cancer Burden 
Table 4

Randomized clinical trials investigating the clinical utility of Ki67 and PEPI scores

\begin{tabular}{|c|c|c|c|c|}
\hline Study & Profile & Initial Treatment & Randomization & Primary Endpoint(s) \\
\hline $\begin{array}{l}\text { NCT01953588 } \\
\text { ALTERNATE }\end{array}$ & $\begin{array}{l}\text { Phase IIb-III (n: } \\
\text { 2820) } \\
\text { T2-T4 } \\
\text { Allred 6-8 }\end{array}$ & $\begin{array}{l}\text { A: Anastrozole } \\
\text { B: Fulvestrant } \\
\text { C: Fulv + Ana }\end{array}$ & $\begin{array}{l}\mathbf{4 / 1 2} \text { weeks } \\
\text { Ki67 }<10 \% \rightarrow \text { ET } \times 24 \mathrm{wks} \\
\text { Ki67 }>10 \% \rightarrow \text { CT } \times 24 \mathrm{wks} \\
\text { After Surgery } \\
\text { PEPI } 0 \rightarrow \text { ET } \times 5 \text { ys }\end{array}$ & $\begin{array}{c}\text { Modified PEPI + Ki67 } \\
\text { at 4/12 wks }\end{array}$ \\
\hline $\begin{array}{c}\text { NCT00265759 } \\
\text { ACOSOG Z1031-B }\end{array}$ & $\begin{array}{l}\text { Phase III (n: 610) } \\
\text { Stage II-III } \\
\text { Allred 6-8 }\end{array}$ & $\begin{array}{l}\text { A: Anastrozole } \\
\text { B: Exemestane } \\
\text { C: Letrozole }\end{array}$ & $\begin{array}{l}\text { 2-4 weeks } \\
\text { Ki67 }<10 \% \rightarrow \text { ET } \\
\text { Ki67 }>10 \% \rightarrow \text { CT or } \\
\text { Surgery } \\
\text { After Surgery } \\
\text { PEPI } 0 \rightarrow \text { ET alone }\end{array}$ & $\begin{array}{c}\text { ORR } \\
\text { pCR for CT arm }\end{array}$ \\
\hline NCT01779206ADAPT HR+/HER2- & $\begin{array}{l}\text { Phase III (n: 4000) } \\
\text { N0-1 and } \\
\text { Oncotype RS 12- } \\
25\end{array}$ & ET & $\begin{array}{l}\text { 3 weeks } \\
\text { Ki67 }<10 \% \rightarrow \text { ET } \\
\mathrm{Ki} 67>10 \% \rightarrow \mathrm{CT}\end{array}$ & RFS \\
\hline $\begin{array}{l}\text { NCT02592083 } \\
\text { PREDIX-A }\end{array}$ & $\begin{array}{l}\text { Phase II (n: 200) } \\
\text { Pre and Post- } \\
\text { menopausal } \\
\text { Luminal A: ER } \\
\text { 50\% \& Ki67 } \\
\underline{20 \%}\end{array}$ & ET & $\begin{array}{l}\quad \mathbf{6} \text { weeks } \\
\text { Ki67 } 20 \% \text { : } \\
\text { A: ET } \times 10 \text { wks } \\
\text { B: ET + Palbociclib ×10 } \\
\text { wks } \\
\text { Ki67 <20\%: } \\
\text { C: } \text { ET + Palbociclib } \times 10 \\
\text { wks }\end{array}$ & ORR at $16 \mathrm{wks}$ \\
\hline $\begin{array}{l}\text { NCT02603679 } \\
\text { PREDIX-B }\end{array}$ & $\begin{array}{l}\text { Phase II (n: 200) } \\
\text { Luminal B or } \\
\text { Luminal A (Ki67 } \\
>20 \%) \& \text { age }<40 \\
\text { or N1 }\end{array}$ & $\begin{array}{l}\text { A: Paclitaxel } \\
\text { B: ET+ Palbociclib }\end{array}$ & $\begin{array}{l}12 \text { weeks } \\
\text { If not progressive disease: } \\
\mathrm{A} \rightarrow \mathrm{B} \times 12 \mathrm{wks} \\
\mathrm{B} \rightarrow \mathrm{A} \times 12 \mathrm{wks}\end{array}$ & ORR at 24 wks \\
\hline NCT01613560 & $\begin{array}{l}\text { Phase II (n: 404) } \\
\text { T2-3 } \\
\text { ER or PR > } 50 \%\end{array}$ & ET & $\begin{array}{l}\text { 16-20 weeks } \\
\text { PEPI } 0-1 \rightarrow \text { ET } \times 5 \text { ys } \\
\text { PEPI } 2-4 \rightarrow \text { Randomized } \\
\text { to: A: } E T \times 5 \text { ys } \\
\text { B: } \text { CT }+ \text { ET } \times 5 \text { ys }\end{array}$ & RFS \\
\hline
\end{tabular}

ET: Endocrine Therapy; ORR: Overall Response Rate; PD: Progressive Disease; CT: Chemotherapy; RFS: Relapse Free Survival; pCR: Pathologic Complete Response 